\title{
Conventional Penetrating Keratoplasty Versus Femtosecond Laser Assisted Penetrating Keratoplasty
}

Mohamed Selim El Kadi, Mahmoud Mohamed Ismail, Mohamed Ahmed El Malah, Suzan Fouad Mohamadia*

Ophthalmology Medicine and Surgery Department, Al-Azhar University

*Corresponding author: Suzan Mohamadia, Mobile: (+20)01001994959, E-Mail: dr_suzi79@ yahoo.com

\begin{abstract}
Purpose: due to introduction of femtosecond Laser technology as new tool in penetrating keratoplasty (PKP), this study aims to compare this new tool and conventional PKP, also aims to compare between different shapes of femtosecond Laser (FSL) assisted PKP. Patients and methods: 40 eyes with different corneal pathologies were included in this study and they were categorized in to 2 groups. 20 eyes underwent penetrating keratoplasty by using manual trephination (I) and 20 eyes underwent PKP by using FSL assisted trephination (II).

Results: femtosecond Laser assisted penetrating keratoplasty (FLAK) substantially improved wound healing, speeds up visual recovery and improved BCVA as it decreased MRA and corneal steepening but consumed more operative time. Conclusion: FLAK is the future in corneal graft surgery, where healing may not be a problem in the postoperative period.
\end{abstract}

Keywords: Conventional PKP, FSL assisted PKP and wound healing.

\section{INTRODUCTION}

Penetrating keratoplasty (PK) has emerged as a relatively safe means of restoring vision in corneal opacities and irregularities. One of the critical steps in PK is wound closure, as adequateness of sutures will postoperatively determines not only the presence of astigmatism but also presence or even graft failure ${ }^{(\mathbf{1})}$.

Conventional penetrating keratoplasty requires relatively tight sutures to hold edges together until healing is sufficient to the intraocular pressure. This usually takes about one year. Astigmatism is often of irregular type. The most important factors of adequate, rapid wound healing and lower postoperative astigmatism are centration of corneal trephination in donor and recipient, the maintenance of perpendicularity and the exact antero-posterior

\section{AIM OF THE WORK}

This study aims to compare FSL assisted PKP as a new tool and conventional PKP, also aims to compare between different shapes of FSL assisted PKP.

\section{PATIENTS AND METHODS}

This work had been conducted at ophthalmic medicine and surgery department, Al-Hussein and Sayed Galal Hospitals, Faculty of Medicine, ALAzhar University and at Noor EL-Hayet Hospital during the period from March 2016 till October 2018.

Ethical approval: The study was approved by Ethics Board of the Faculty of Medicine, AlAzhar University. There was also a written consent from patients.

Forty eyes were included in this study of males and females (20 male and 18 female). All patients were suffering from corneal pathology as keratoconus grade 4, decompensated cornea, corneal dystrophies and corneal opacities and were in need for penetrating alignment of wound, also parameters of graft and recipient cutting, all of the previous can be achieved easily than conventional cases. The femtosecond Laser is one of the most revolutionary in the recent medical technology. It has been used mainly for creation of corneal flabs for Laser insitu keratomileusis as an alternative to mechanical microkeratome. This technology has enabled us to apply for corneal transplantation ${ }^{(2)}$.

As further advances in hardware and software technology enable pulsed to be applied in different patterns and shapes, mushroom shaped, top hat and zigzag ${ }^{(3)}$, also straight cut with accurate depth and diameter with accurate measurements and done by Visu Max with $500 \mathrm{~Hz}$ repetition rate has been reported $^{(3)}$.

keratoplasty. They were categorized in to 2 groups. Group (I): twenty eyes underwent penetrating keratoplasty by using manual trephination. Group (II): twenty eyes underwent PKP by using FSL assisted trephination, mushroom shaped, top hat or straight cut.

Inclusion criteria: all patients fulfilled the following criteria

- Patients with corneal opacity

- Advanced keratoconus not suitable for hard contact lenses or corneal rings

\section{Exclusion criteria :}

- Unstable corneas or "open eyes" like corneal perforation with lost or very shallow anterior chamber.

- Pseudophakic with anterior chamber IOL.

- Uncontrolled glaucoma.

- Active uveitis or before 6 months of recovery.

- Active viral or bacterial infections.

- Very severe, vascularized corneal opacities like that due to chemical injuries

- Extreme of ages less than 19 years and more than 70 years HTH-PKP patients 
Preoperatively all patients underwent

History: was taken with special attention to the patient's age; important factors regarding wound healing, and symptoms suggesting pathology affecting the other eye like early Fuchs' corneal dystrophy with corneal guttata. Also inquiry about previous complicated cataract surgery, with or without IOI implantation. Also cases with dense opacities were evaluated with ERG and VEP

Examination: All eyes were subjected to full ophthalmological examination; including BCVA, error of refraction (if possible) using automated refractometer (Topcon), slit-lamp examination (HaagStreit), fundus examination (if possible), ocular ultrasonography, and intraocular pressure (IOP) measurement by indentation tonometry (Schiotz tonometer), also Tonopen or ocular response analyser was used ; because applanation tonometry was not possible in most of the cases preoperatively with irregular and/or scarred corneas. Pentacam was also used for cases with keratoconus and Anterior segment OCT for corneal dystrophies.

\section{Follow up:}

Cases of both groups were followed up for a period of 12 months; each patient was examined daily for the first three postoperative days, then weekly during first month, then at three months, 6 months and 12 months. In each visit anterior chamber depth, anterior surface alignment, refraction and BCVA were observed.

Each group was evaluated for:

1. Wound tightness: It was observed intraoperatively during suture taking and by the end of the surgery.

2. BCVA: at $1^{\text {st }}, 3^{\text {rd }}, 6^{\text {th }}$ months and $12^{\text {th }}$ months

3. Manifest refraction astigmatism: mean MRA was measured before and after removal of sutures.

4. Pentacam: K-readings and patterns were assessed preoperatively and postoperatively at $6^{\text {th }}$ and $12^{\text {th }}$ months to evaluate corneal thickness, corneal topography and astigmatism.

5. Sutures removal timing.

6. Graft rejection incidence within 1 year.

. Vertical alignment of the wound at graft host junction. Postoperative complications were observed and they were divided into early and late postoperative complications

- Early complications: included wound leak, complications related to epithelial healing, filamentary keratitis, suture related complications, I.O.P. related complications, anterior segment inflammation, choroidal detachment and hemorrhage, infection and primary graft failure.

- Late complications: included graft rejection, astigmatism, glaucoma, loose suture, infectious keratitis and endophthalmitis.

\section{Statistical analysis}

Recorded data were analyzed using the statistical package for social sciences, version 20.0 (SPSS Inc., Chicago, Illinois, USA). Quantitative data were expressed as mean \pm standard deviation (SD). Qualitative data were expressed as frequency and percentage.

\section{The following tests were done:}

Independent-samples t-test of significance was used when comparing between two means.

- Chi-square $\left(\mathrm{x}^{2}\right)$ test of significance was used in order to compare proportions between two qualitative parameters.

- The confidence interval was set to $95 \%$ and the margin of error accepted was set to $5 \%$. The p-value was considered significant as the following:

- Probability (P-value)

- P-value $<0.05$ was considered significant.

- P-value $<0.001$ was considered as highly significant.

- P-value $>0.05$ was considered insignificant.

\section{RESULTS}

Table (1): Manifest refraction astigmatism (MRA)

\begin{tabular}{|c|c|c|c|c|c|c|c|c|}
\hline Conventional & Mean & $\mathrm{N}$ & \begin{tabular}{|c|} 
Std. \\
Deviation
\end{tabular} & $\begin{array}{l}\text { Std. Error } \\
\text { Mean }\end{array}$ & Improvement & $\mathrm{t}$ & Df & Sig. (2-tailed) \\
\hline After suture removal & 5.09 & 19 & 1.92690 & 0.44206 & \multirow{2}{*}{$-57 \%$} & & & \\
\hline Before suture removal & 11.78 & 19 & 4.61734 & 1.05929 & & -9.237 & 18 & $<0.000$ \\
\hline
\end{tabular}

Table (2): M.R.A

\begin{tabular}{|c|c|c|c|c|c|c|c|c|}
\hline FsL ass & Mean & $\mathrm{N}$ & $\begin{array}{c}\text { Std. } \\
\text { Deviation }\end{array}$ & $\begin{array}{l}\text { Std. Error } \\
\text { Mean }\end{array}$ & Improvement & \multirow[t]{2}{*}{$\mathrm{t}$} & \multirow[t]{2}{*}{ Df } & \multirow[t]{2}{*}{ Sig. (2-tailed) } \\
\hline After suture removal & 4.63 & 18 & 2.68198 & 0.63215 & \multirow{2}{*}{$-36 \%$} & & & \\
\hline Before suture removal & 7.28 & 18 & 4.43407 & 1.04512 & & -4.192 & 17 & $<0.001$ \\
\hline
\end{tabular}

After we make a statistical analysis for manifest refraction astigmatism for cases in both groups we found that there was a statistically difference $(\mathrm{P}<0.001)$ between improvement of manifest refraction astigmatism after suture 
removal in case of group (II) than that in case of group (I) also between figures in group (II) after suture removal and in group (I) also after suture removal (Tables 1,2)

Table (3): K READINGS

\begin{tabular}{|c|c|c|c|c|c|c|c|c|c|c|}
\hline \multirow[t]{2}{*}{ After 6 moths } & \multirow[t]{2}{*}{ Surgery } & \multirow[t]{2}{*}{$\mathrm{N}$} & \multirow[t]{2}{*}{ Mean } & \multirow[t]{2}{*}{$\begin{array}{c}\text { Std. } \\
\text { Deviation }\end{array}$} & \multirow[t]{2}{*}{$\begin{array}{l}\text { Std. } \\
\text { Error }\end{array}$} & \multicolumn{2}{|c|}{$\begin{array}{c}\text { Levene's Test } \\
\text { for Equality } \\
\text { of Variances }\end{array}$} & \multicolumn{3}{|c|}{$\begin{array}{l}\text { t-test for Equality of } \\
\text { Means }\end{array}$} \\
\hline & & & & & & $F$ & Sig. & $\mathrm{t}$ & Df & $\begin{array}{l}\text { Sig. (2- } \\
\text { tailed) }\end{array}$ \\
\hline $\begin{array}{c}\text { Average } \mathrm{k} \\
\text { readings }\end{array}$ & FsL ass & 18 & 43.99 & 2.76 & 0.65 & 3.42 & 0.07 & 0.31 & 35.00 & 0.76 \\
\hline
\end{tabular}

Table (4): K READINGS

\begin{tabular}{|c|c|c|c|c|c|c|c|c|c|c|}
\hline \multirow[t]{2}{*}{12 mothes } & \multirow[t]{2}{*}{ surgery } & \multirow[t]{2}{*}{$\mathrm{N}$} & \multirow[t]{2}{*}{ Mean } & \multirow[t]{2}{*}{$\begin{array}{c}\text { Std. } \\
\text { Deviation }\end{array}$} & \multirow{2}{*}{$\begin{array}{l}\text { Std. } \\
\text { Error } \\
\text { Mean }\end{array}$} & \multicolumn{2}{|c|}{$\begin{array}{c}\text { Levene's Test } \\
\text { for Equality of } \\
\text { Variances } \\
\end{array}$} & \multicolumn{3}{|c|}{ t-test for Equality of Means } \\
\hline & & & & & & $\mathrm{F}$ & Sig. & $\mathrm{t}$ & Df & Sig. (2-tailed) \\
\hline \multirow{2}{*}{$\begin{array}{l}\text { Average k } \\
\text { readings }\end{array}$} & Conventional & 19 & 43.5842 & 3.70784 & 0.85064 & \multirow[t]{2}{*}{0.162} & \multirow[t]{2}{*}{0.690} & \multirow{2}{*}{0.730} & \multirow{2}{*}{35} & \multirow{2}{*}{0.470} \\
\hline & FsL ass & 18 & 42.7056 & 3.61425 & 0.85189 & & & & & \\
\hline
\end{tabular}

While statistically analyzing mean values of $\mathrm{K}$ readings of cases in both groups at $6^{\text {th }}$ months and after 1 year postoperative we found that the values were nearer to normal in case of group (II) than in group (I) $\mathrm{P}<0.001$.

Pentacam was performed after 6 and 12 months in both groups. Improvement of K-readings and corneal patterns through the Pentacam is a reflection for improvement of corneal pathologies as keratoconus or dystrophies. And it was a guide line for us during suture removal, as it indicates accurately axis, degree and pattern of astigmatism. It also shows corneal edema through corneal thickness. Evaluation of k-readings, topographic pattern and corneal thickness is an indicator of wound healing as very low k-readings 33 or below is an indicator for a flat host graft junction mostly non healed wound. Also the thinner the junction (the peripheral corneal thickness) the more the number of keratocytes involved in healing process, the more the mature is the wound .

\section{Incidence of graft rejection:}

\section{Vertical alignment: \\ In group (II) FSL assisted group}

Case 6 in group (II) FSL assisted group has vertical misalignment as donor button wing looser of uncut graft which is manually cut with lower wing lost in the upper temporal area as femto Laser undo the cut this leaded to anterior and posterior misalignment.

This also leaded to posterior wound gap.

In Group (I) conventional assisted PKP:

Case 2 there was vertical misalignment due to decentration of trephination of recipient which leaded to difference in thickness between graft and recipient at host graft junction. Also in case 7 there was vertical misalignment due to decentration of trephination of the donor button graft leading to anterior misalignment .

Vertical alignment in group I conventional PKP was depending on suturing skills more than in case of group II FSL assisted PKP.

\section{DISCUSSION}

Femtosecond Laser technology has been shown to achieve greater precession and accuracy of donor and recipient corneal wound incision compatibility compared with conventional manual blade trephination ${ }^{(7)}$.

In addition perfect apposition of FSL-assisted multipaner incision of donor cornea with parallel multipanner incisions of recipient corneal bed is not achievable with manual trephination technique even with beveled incision patterns as such the FSL assisted incision provides greater stability and increases resistance to ocular trauma and to increase I.O.P., which may lead to dehiscence ${ }^{(3)}$.

There are variety of incision patterns. Zigzag incision pattern was described to be more biomechanically favorable by providing smooth transition along the anterior surface and excellent host graft alignment ${ }^{(4)}$.

Mushroom shaped was chosen for patients with keratoconus as it provides more healthy stromal tissue to anterior half of corneal graft compared to its posterior half. This feature may lend support to the biomechanical structure of graft periphery after surgery and improve the graft wound stability consequently decreasing the extent of final astigmatism and supplying the required concentration of transplanted donor endothelium ${ }^{(5)}$. 
To date various incision patterns for PKP have been described for FSL technology; the most commonly reported one was zigzag profile ${ }^{(5)}$.

Farid et al. ${ }^{(8)}$ showed that the postoperative astigmatism was lower in the zigzag FLEK group compared with the conventional group and that the former had faster visual rehabilitation.

Rush et al. ${ }^{(9)}$ added that sutures can be removed earlier in zigzag FLEK group compared with manual PKP group.

Another pattern was top hat profile. Nubile $\boldsymbol{e t}$ al. (10) compared the outcomes of top hat FLEK to those with conventional PKP and manual "top hat" PKP. The mean clynder_was similar in both group but mean time of suture removal was shorter in top hat FLEK group.

In his retrospective study; although mushroom FLEK incision demonstrated less induced astigmatism after keratoplasty compared with conventional PKP; the final postoperative CDVA was similar in 2 groups after suture removal after one year of follow up.

The mean manifest postoperative astigmatism was significantly lower than that in conventional PKP group after 1 year and suture.

Refractive error blurring strength was significantly lower in M-FLEK group compared with manual PKP group at the $12^{\text {th }}$ month after surgery

Larger corneal grafts resulted in less astigmatism after surgery ${ }^{(11)}$; however they are closer to limbus and have a greater risk for corneal graft rejection.

Poole and Ficker ${ }^{(12)}$ found that mushroom profile combines 3 advantages; it replaces larger anterior lamellar surface, it preserve a large corneal endothelial layer of recipient and allow a larger gap from limbal area.

\section{CONCLUSION}

- FSL-assisted PKP substantially speeds up suture removal and speeds up visual recovery, also it decrease high manifest refraction astigmatism and steepness confirmed by Pentacam taken before and after the operation in the two group of patients.

- On other hand it is relatively cumbersome and time consuming during donor graft preparation when compared to conventional PKP it is a drawback.

- FSL assisted PKP allows the surgeon to consider any imaginable incision shape, as mushroom shape, zigzag and top-hat with the desirable depth and diameters with accurate measurements to easily match donor and recipient dimensions, making (no stitch) keratoplasty is the future in corneal graft surgery, where delayed healing may not be a problem in post PKP period.

- Larger randomized series of patients with longer follow up are needed.

\section{REFERENCES}

1. Ma JF, Rapuano CJ, Tseng SC et al. (2016): Outcomes of wound dehiscence post-penetrating. Cornea, 35:778-83.

2. Sietz B, Langenbucher A, Mullins $\mathbf{R}$ et al. (2005): Perspectives of excimer laser -assisted PKP. Ophthalmologe, 108:385-95.

3. Deng ML, Li LN, Huang LF et al. (2015): Effect of translation and rotation fitting on analysis of corneal topography. J Med Eng Technol., 39(6):309-15.

4. Jones YJ, Goins KM, Sutphin JE et al. (2008): Comparison of the femtosecond laser (IntraLase) versus manual microkeratome (Moria ALTK) in dissection of the donor in endothelial keratoplasty: initial study in eye bank eyes. Cornea, 27(1):88-93.

5. Ghaznawi N, Chen ES (2010): Descemet's stripping automated endothelial keratoplasty: innovations in surgical technique. Current Opinion in Ophthalmology, 21(4):283-287.

6. Ratkay-Traub I, Juhasz T, Horvath C et al. (2001): Ultra-short pulse (femtosecond) laser surgery: initial use in LASIK flap creation. Ophthalmology Clinics of North America, 14(2):347-355.

7. Bahar I (2008): FSL assisted PKP:stability evaluation of different wound configuration. Cornea, 27:209-11.

8. Farid M, Stenier RF, Gaster RN et al. (2009): A comparison of PKP performed with femtosecond laser zigzag incision versus conventional blade trephination. Ophthalmology, 16(9);1638-43.

9. Rush SW, Mathers WD, Cabezas M et al. (2011): comparison of FSL assisted PKP versus conventional keratoplasty. Ophthalmology, 118 ;486-91.

10. Nubile $M$, Lanzini $M$, Lanzini $M$ et al. (2009): Femtosecond laser arcuate keratotomy for correction of high astigmatism after keratoplasty. Ophthalmology, 116 (6): 1083-1092.

11. Mehta JS, Shilbayeh R, Por YM et al. (2008): Femtosecond laser creation of donor cornea buttons for Descemet-stripping endothelial keratoplasty. Journal of Cataract and Refractive Surgery, 34(11):1970-1975.

Poole TR and Ficker L (2006): Astigmatic keratotomy for post-keratoplasty astigmatism. J Cataract Refract Surg., 32:1175-1179. 